\title{
Behavioural variability among captive African elephants in the use of the trunk while feeding
}

\author{
Maëlle Lefeuvre ${ }^{\text {Corresp., } 1,2}{ }^{2}$ Patrick Gouat ${ }^{3}$, Baptiste Mulot ${ }^{4}$, Raphaël Cornette $^{5}$, Emmanuelle Pouydebat ${ }^{1}$ \\ 1 Adaptive mechanisms and evolution, UMR 7179, CNRS/MNHN MECADEV, Paris, France \\ 2 Institute of Environmental Sciences, Faculty of Biology, Jagiellonian University, Cracow, Poland \\ 3 Laboratoire d'Éthologie Expérimentale et Comparée E.A. 4443, Université Sorbonne Paris Nord, Villetaneuse, France \\ 4 Zooparc de Beauval \& Beauval Nature, 41110 Saint-Aignan, France \\ 5 Institut de Systématique, Evolution, Biodiversité (ISYEB), UMR 7205, Muséum national d'Histoire naturelle, CNRS, SU, EPHE, UA, CP 50, Paris, France \\ Corresponding Author: Maëlle Lefeuvre \\ Email address: maelle.lefeuvre@doctoral.uj.edu.pl
}

The Proboscideans, an order of mammals including elephants, are the largest of the Earth lands animals. One probable consequence of the rapid increase of their body size is the development of the trunk, a multitask highly sensitive organ used in a large repertoire of behaviours. The absence of bones in the trunk allows a substantial degree of freedom for movement in all directions, and this ability could underlie individual-level strategies. We hypothesized a stronger behavioural variability in simple tasks, and a correlation between the employed behaviours and the shape and size of the food. The observations of a captive group of African elephants allowed us to create a complete catalogue of trunk movements in feeding activities. We noted manipulative strategies and impact of food item properties on the performed behaviours. The results show that a given item is manipulated with a small panel of behaviours, and some behaviours are specific to a single shape of items. The study of the five main feeding behaviours emphasizes a significant variability between the elephants. Each individual differed from every other individual in the proportion of at least one behaviour, and every behaviour was performed in different proportions by the elephants. Our findings suggest that during their lives elephants develop individual strategies adapted to the manipulated items, which increases their feeding efficiency. 


\section{${ }_{1}$ Behavioural variability among captive}

\section{African elephants in the use of the trunk}

\section{3 while feeding}

4

5 Maëlle Lefeuvre ${ }^{1,2}$, Patrick Gouat ${ }^{3}$, Baptiste Mulot ${ }^{4}$, Raphaël Cornette ${ }^{5}$, Emmanuelle

6 Pouydebat ${ }^{2}$

7

$8{ }^{1}$ UMR 7179, CNRS/MNHN MECADEV Adaptative mechanisms and evolution, Paris, France

92 Present address : Institute of Environmental Sciences, Faculty of Biology, Jagiellonian

10 University, Cracow, Poland

${ }^{3}$ Laboratoire d'Éthologie Expérimentale et Comparée E.A. 4443, Université Sorbonne Paris

Nord, Villetaneuse, France

${ }^{4}$ Zooparc de Beauval \& Beauval Nature, 41110 Saint-Aigan, France

${ }^{5}$ Institut de Systématique, Evolution, Biodiversité (ISYEB), UMR 7205, Muséum national 
20 Correspondence:

21 Maëlle Lefeuvre: maelle.lefeuvre@doctoral.uj.edu.pl

22 ORCID: https://orcid.org/0000-0003-4291-134X 
23 The Proboscideans, an order of mammals including elephants, are the largest of the Earth lands 24 animals. One probable consequence of the rapid increase of their body size is the development of 25 the trunk, a multitask highly sensitive organ used in a large repertoire of behaviours. The absence 26 of bones in the trunk allows a substantial degree of freedom for movement in all directions, and 27 this ability could underlie individual-level strategies. We hypothesized a stronger behavioural variability in simple tasks, and a correlation between the employed behaviours and the shape and size of the food. The observations of a captive group of African elephants allowed us to create a complete catalogue of trunk movements in feeding activities. We noted manipulative strategies and impact of food item properties on the performed behaviours. The results show that a given item is manipulated with a small panel of behaviours, and some behaviours are specific to a single shape of items. The study of the five main feeding behaviours emphasizes a significant variability between the elephants. Each individual differed from every other individual in the proportion of at least one behaviour, and every behaviour was performed in different proportions by the elephants. Our findings suggest that during their lives elephants develop individual strategies adapted to the manipulated items, which increases their feeding efficiency. 
40 Manipulation of food and tools has a central role in strategies and survival of several different

41 species (Sustaita et al., 2013). Although many mammals have been studied in this regard, the

42 literature on primates dominates this field of research. Primates use their anterior limbs and more

43 specifically hands and fingers to manipulate the objects of their interest. Hand grasping, involved

44 in many daily activities, has been extensively studied in primates which are characterized by the

45 ability to individualize their fingers and thus to perform complex grasping and manipulation

46 tasks (e.g. Christel, 1993; Christel et al., 1998; Christel and Billard, 2002; Crast et al., 2009;

47 Jones-Engel and Bard, 1996; Pouydebat et al., 2009, 2011). Grasping and manipulative strategies

48 vary according to the task and the properties of the objects grasped (Bardo et al., 2016a and

49 2016b; Fabre et al., 2013; Peckre et al., 2016). Indeed, the size and the mobility of the object, or

50 the complexity of the task clearly affect the grasping techniques and the hand preference (Bardo

51 et al., 2015; Peckre et al., 2019; Pouydebat et al., 2010; Reghem et al., 2011). In addition, inter-

52 individual differences in object manipulation behaviours have been quantified in primates (Bardo

53 et al., 2016, 2017). Finally, species lacking suitable hands are also able to manipulate items with

54 a high precision, such as birds with their beaks (Brunon et al., 2014) and elephants with their

55 trunks (Hart et al., 2001).

56 The elephants' trunk is involved in many activities such as feeding and drinking, investigation of

57 the environment, vocalization and social behaviours, and also in making and using tools

58 (Haakonsson \& Semple, 2009; Hart et al., 2001; Fowler \& Mikota, 2006; Plotnik et al., 2011;

59 Rasmussen \& Munger, 1996; Shoshani, 1998; Yang et al., 2006). This organ is usually compared

60 with the hand of primates because of its agility and use in various contexts. The distal part of the

61 trunk has prehensile and sensitive capacities helpful for investigation and manipulation. 
62 Different manipulative strategies can be observed in elephants during feeding, depending mostly

63 on the species and the size of the food items (Racine, 1980). The two well-developed fingers of

64 the trunk of the African elephants (Loxodonta sp.) allow them to pinch small objects with a high

65 precision (Hoffmann et al., 2004) but gripping can be performed differently, e.g. by wrapping the

66 whole trunk around the item, which is favoured by Asian elephants (Elephas maximus). When

67 the item is large, the elephants are more likely to wrap it, and they usually secure the food with

68 the distal part of their trunk, using a vacuum.

69 The trunk is formed by the fusion of an extended nose and the upper lip (Rasmussen \& Munger,

70 1996), reaching 1.5-2 meters long in adult elephants and mainly composed of muscles(between

71 100,000 and 150,000, Shoshani, 1998; Yang et al., 2006). Thanks to those muscles, the elephants

72 are able to extend, bend and twist their trunk in both directions by a right-hand and a left-hand

73 array of the helical muscles (Kier \& Smith, 1985; Fowler \& Mikota, 2006; Shoshani, 1998; Yang

74 et al., 2006). This organization enables them to hold heavy loads as well as catching very small

75 items with a high precision.

76 Differences between elephants species have been investigated for some behaviours. However,

77 usage of the trunk is usually integrated in more global behavioural categories. Adams and Berg

78 (1980) detailed 21 behaviours of captive African elephants, but only seven of them implied the

79 trunk. These included investigation and manipulation, trunk to mouth and eating. Fowler and

80 Mikota (2006) explored mostly the chemosensory behaviours and only some of them involved

81 the trunk such as the trunk tip contacts, pinching, blowing, sucking and drinking. No inter-

82 individual differences were evaluated, and to our knowledge no studies investigated the

83 individual-level strategies in trunk use. 
84 The aim of our study was to make a detailed catalogue of the behaviours involving the use of the

85

86

87

88

89

90

91

92

93

94

95

96

97

98

99

100

101

102

103

104

105

106

trunk in captive African elephants. We qualified the uses of the trunk at the movement level, taking into account the properties of the manipulated items as well as the individual preferences for the different strategies. We hypothesised that (i) the simpler the task (few constraints, like grasping big items) the stronger are the inter-individual differences. On the contrary for more complex tasks involving high constraints, like gripping small items or performing precise tasks, we expected less inter-individual differences. We also hypothesised that (ii) the strategy to manipulate a specific item depends on its size and shape.

\section{METHODS}

\section{Animal Subjects and Housing Conditions}

This study took place at the ZooParc of Beauval from 1st of February to 5th of April 2019. Six African elephant of savannah (Loxodonta africana) females were observed. They were divided into two groups: group A encompassed Juba (named A1 thereafter, 32 year old), Ashanti (A2, 16 year old), Tana (A3, 32 year old) and M'Kali (A4, 30 year old) whereas Marjorie (B1, 33 year old) and N'Dala (B2, 30 year old) constituted the group B. Juba, Ashanti and Tana originated from Knowsley Safari Park (U.K.) and arrived at Beauval in 2017. The other three elephants came from the Longleat Zoo (U.K.) and arrived at Beauval in 2003. N'Dala was blind since one year, having a cataract on one eye and retinal detachment on the other. The two groups were never merged, but inside the building the elephants of one group could hear, touch and smell the elephants of the other group through the bars. Encounters of elephants from the two groups were often organized by the keepers with only some of the individuals, in order to merge the groups into a single one in the future. At the beginning of the observation period only one individual of 
107 each group participated to those encounters (N'Dala and M'Kali), then Ashanti had been added.

108 No observations were conducted during those particular periods.

109 During the cold season, the elephants were housed in the building divided into nine boxes. Group

110 A occupied four boxes of $58.5 \mathrm{~m}^{2}$ and one of $307 \mathrm{~m}^{2}$ (total of $541 \mathrm{~m}^{2}$ ), whereas group B

111 occupied four boxes (total of $348 \mathrm{~m}^{2}$ ). On warm days, the elephants get out for a couple of hours

112 in a cement-flooring area connected with the building. As soon as the weather conditions became

113 more favourable, elephants spent up to 10 hours per day into the parklands. In this study we

114 observed elephants only indoor.

115 Elephants had constant access to food in the following categories: hay, tree branches, vegetables

116 and apples. Hay was distributed in every box, in elevated nets which were filled twice a day, in

117 the morning and in the afternoon. Elephants had access to two to three meters long branches of

118 various European trees (i.e. beech, hornbeam, birch) and bamboo. The branches were cut each

119 day and distributed during the filling of the hay nets, in the amount of at least one branch or two

120 bamboos per elephant. We considered bamboos as branches items in our observations because

121 their shape and size were similar. In the morning the branches were laid on the ground outside

122 the boxes, near the bars, while in the afternoon, after cleaning of the areas, they were fixed at the

123 bars and toy installations and laid in the boxes.

124 Pieces of seasonal European vegetables (a few cubic centimetres, various species such as

125 beetroot, carrots, celeriac, parsnip, fennel, sweet potato, cabbage, cucumber) were distributed

126 three times per day: at the beginning of the working day, at the beginning of the afternoon and at

127 the end of the working day. They were scattered inside the boxes and outside along the bars.

128 Finally, apple slices were distributed one by one to capture the elephants' attention during the

129 doors' opening and elephants' transfer between boxes, five times per day when elephants spent 
130 the day indoor. During these interactions, we observed elephants' strategies to manipulate apple

131 slices. In our records, we differentiated them from vegetable pieces, because of their different

132 properties. Apple slices were flatter and almost always distributed on the cement flooring, while

133 vegetable pieces were more cubic and also available on the sand flooring.

134 We worked on captive animals housed in their building, from a distance of approximately three

135 meters from the bars of the enclosure. These conditions offered many advantages, assuring

136 individual recognition which is essential when studying individual strategies. The proximity to

137 the elephants allowed precise live observations of the movements. Finally, in captivity, the

138 conditions were more standardized than in the wild, thanks to the stable feeding schedule and

139 invariable properties of food items.

141 Ethical note

142 Observations were made following the rules of the zoo and from the security zone, as far as

143 possible from the bars and the elephants. No interactions of the observer with the animals

144 occurred during observations. Only the keepers had their usual interactions with the elephants

145 (moving them, giving them food, and talking to them).

\section{Behavioural Observations}

148 Our aim was to study the use of the trunk by the elephants during their daily activity. Preliminary

149 observations allowed us to identify 65 behaviours displayed in different contexts: feeding, body

150 care, playing, resting, social behaviours and exploration. We predicted a link between the

151 activity and the specific use of the trunk. We also expected that elephants might differ in their

152 use of the trunk during a given task. 
153 We adapted our observation time to the keepers' schedule, in order to avoid interruptions during

154 behavioural sampling if animals were transferred from indoor to outdoor or if the groups'

155 composition was modified by the isolation of an individual. Observations began after the end of

156 the daily training (at around 1000 hours) and lasted during the keepers' presence hours in the

157 building, until 1900 hours. No observations occurred between 1230 hours and 1400 hours.

158 Data was collected using the focal animal sampling (Altmann, 1974). We defined a sample as a

159 continuous observation of one individual and a session as a sequence of six samples, one for

160 each elephant. Each sample lasted 15 minutes and one to three sessions were performed per

161 observation day. Before each session, the sampling order was defined thanks to a simulator of

162 random lists. A total of 92 samples were collected, with 14 to 17 samples per individual. In the

163 afternoon some elephants had access to the cement-flooring outdoor area, and the conditions of

164 observation were not comparable to the usual conditions. Hence, we skipped the observation of

165 individuals outdoor, which explains the variable number of collected samples per individual.

166 During the observation of an elephant, behaviours involving the trunk were scored continuously

167 as occurrences, and the type of activity (e.g. feeding, body care) and the type of manipulated

168 object were reported. The duration of the activity was recorded but the behaviours were

169 considered as events. In this article we present the results related to the feeding behavioural

170 category (listed in Table 1). Feeding behaviours were defined as every movement related to food

171 or water acquisition, manipulation and consumption, as well as mouth's contacts with the end of

172 the trunk while eating (i.e. Trunk to mouth and Contact to mouth in Table 1).

173

174 Data Analysis

175 As described in the literature, feeding was the main activity of the elephants. They spent $72.7 \pm$

$1765.8 \%$ (mean \pm S.D.) of their time feeding and feeding behaviours corresponded to $77.9 \pm 4.7 \%$ 
177 of all the occurrences of behaviours collected. The repertoire of feeding behaviours encompassed

17819 different behaviours. We collected 15234 occurrences but seven behaviours were rarely $(<4$

179 occurrences) or never observed during the sampling period. Consequently, they were not

180 considered in the analyses.

181 In a first step, we tried to establish a link between the different behaviours and the type of food

182 item manipulated. The six different types of food items were: hay, vegetables, apples, and

183 branches (three sizes). Branches were distributed into three different classes (named b1 to b3

184 thereafter) according to their diameter estimated by eye: $\mathrm{b} 1<5 \mathrm{~mm} ; 1 \mathrm{~cm}<\mathrm{b} 2<2 \mathrm{~cm} ; \mathrm{b} 3>2 \mathrm{~cm}$.

185 For each individual we calculated the number of occurrences of each feeding behaviour

186 according to each type of food. Compared to the other food items, hay was permanently

187 available to the elephants contrary to the other food items and was over-represented in our data

188 set. To avoid this bias we transformed the number of occurrences of the behaviours into the

189 proportion of occurrences, calculated for each food item and each animal. We obtained a table

190 with 10 columns/behaviours and 36 rows ( 6 individuals x 6 types of food items, $N=36$ ). This

191 data set was submitted to a normed Principal Component Analysis (PCA) to detect links between

192 behaviours considered as variables and food items considered as individuals. We then compared

193 the distribution of the coordinates of the "individuals" on the first component axis to test whether

194 different foods items differed. A nonparametric ANOVA with General Scores and a Monte Carlo

195 procedure was performed, followed by paired comparisons between each type of food items

196 using a Fisher Pitman test for paired samples (pairing by individuals). Because multiple

197 comparisons were made, the probabilities were corrected using a Holm-Bonferroni procedure

198 (Holm, 1979) and $P^{\prime}($ the corrected $P$ ) is presented. 
199 Hay was always available to the elephants and most of our data were collected when elephants

200 were manipulating and eating hay $(62.2 \pm 7.9 \%$ of feeding occurrences $)$. The inter-individual

201 differences were tested in comparing the behaviour of the animals when feeding on hay. Because

202 the total number of occurrences varied greatly between animals and samples of a given

203 individual we used the proportions to compare the animals. The comparisons were held only for

204 the five behaviours with enough occurrences. As the two groups did not have exactly the same

205 physical and social environment, we compared the animals of each group separately. All the

206 samples with less than 20 occurrences of behaviour were discarded from the analysis.

207 Consequently the number of samples per animal differs slightly (A1: 12; A2: 10; A3: 11; A4: 9;

208 B1: 14 and B2: 11). For each behaviour, we compared the two individuals of group B with a

209 Fisher Pitman test for independent samples; for the four elephants of group A, we first made an

210 ANOVA with General Scores (with the Monte Carlo procedure) followed by paired comparisons

211 using Fisher Pitman tests for independent samples. The probabilities were corrected using the

212 Holm-Bonferroni procedure and the corrected $P$ value $\left(P^{\prime}\right)$ is reported.

213 The PCA was carried out using Statistica software and the ANOVAs and Fisher Pitman tests

214 were made using StaXact software.

215

216

RESULTS

217 Manipulation Behaviours and Food Items

218 The first two components of the PCA explained $55.3 \%$ of the variance in the correlation matrix

219 (detailed results are presented in supplementary material). Component 1 opposed two groups of 220 behaviours (Fig. 1). Block, pull, adjust, grasp and torsion are on the right side whereas bring to

221 mouth, gather, side pinch and sweep are on the left side. Bundling, shake and pinch are poorly

222 represented on component 1 and were mainly represented on component 2.

PeerJ reviewing PDF | (2020:04:48174:2:0:NEW 9 Jul 2020) 
223 The different types of food items are distributed into three separate groups (Fig. 2): i) hay, ii) the

224 three sizes of branches and iii) vegetables and apples. The analysis of the coordinates on the first 225 component confirms this distribution into three groups. The ANOVA with general scores on the 226 total set of data (i.e. the six initial groups) is highly significant $(P<0.0001)$ and a similar result

227 is obtained when food items are divided into the three groups described above $(P<0.0001)$. The 228 three groups differ significantly from each other (branches-hay: $P^{\prime}=0.001$; branches-vegetable 229 and apple: $P^{\prime}<0.001$; vegetable and apple-hay: $\left.P^{\prime}=0.003\right)$. There are no pairwise differences 230 between the three sizes of branches $\left(\mathrm{b} 1-\mathrm{b} 2: P^{\prime}=0.09 ; \mathrm{b} 1-\mathrm{b} 3: P^{\prime}=0.18 ; \mathrm{b} 2-\mathrm{b} 3: P=0.81\right)$, nor 231 between vegetables and apples $(P=0.24)$.

234 During the manipulation of hay by the elephants, we observed five main behaviours (Fig. 3).

235 These were the three behaviours revealed by the PCA (bundling, shake and pinch; Fig. 1) and 236 two others; grasp and bring to mouth.

237 The use of each of these five behaviours by the elephants was analyzed independently and the 238 comparisons between individuals were made separately inside each group (Fig. 4). Pinch is the 239 most common behaviour used by the six elephants. No difference is found in group B $(P=0.29)$, 240 whereas in group A elephants differed in the frequency of using it (Anova with general scores, $P$ $241<0.0001)$. M'Kali (A4) used this posture significantly more often than the other three elephants $242\left(P^{\prime}<0.012\right.$ whatever the comparison) and Ashanti (A2) used significantly less this posture $\left(P^{\prime}<\right.$ 2430.004 in each pairwise comparison). Juba (A1) and Tana (A3) do not differ significantly $(P=$ $2440.16)$ and occupy an intermediate position.

245 The elephants in group A do not differ significantly in their use of bundling (ANOVA with 246 general scores, $P=0.06)$ and none of the pairwise comparisons is significant $\left(P^{\prime}>0.16\right)$. In 
247 group B, the proportion of bundling is higher for Marjorie (B1) than for N'Dala (B2) $(P=$ $248 \quad 0.026)$.

249 Only the elephants in group A differ significantly in their use of shake (ANOVA with general 250 scores, $P=0.0001$ ) but only marginal differences are found in pairwise comparisons. The

251 proportion is the highest in Tana (A3) but the differences are significant only with Juba (A1) and 252 M'Kali (A4) $\left(P^{\prime}=0.035\right.$ and $P^{\prime}=0.01$ respectively). No difference is found in group B $(P=$ $2530.50)$.

254 The elephants in group A differ significantly in their use of grasp (ANOVA with general scores, $255 P<0.0001)$. The proportion of grasp is the lowest in Juba (A1) and the highest in Ashanti (A2) $256\left(P^{\prime}=0.009\right)$ and the two other elephants occupy intermediate positions and no significant

257 difference is found $\left(P^{\prime}>0.08\right)$. In group $\mathrm{B}$, the proportion of grasp is more than 10 times highest 258 in Marjorie (B1) than in N'Dala (B2) $(P<0.0001)$.

259 The elephants in group A differ significantly in their use of bring to mouth behaviour (ANOVA 260 with general scores, $P<0.0001)$ and this difference is mainly due to the low score of M'Kali

261 (A4) compared to the other three elephants $\left(P^{\prime}<0.0002\right.$ in each pairwise comparison).

262

263

264 265

266

267

268

269

\section{DISCUSSION}

Our results revealed a significant inter-individual variability in the usage of the main feeding behaviours to manipulate a restricted range of food items. Weobserved elephants in an artificial environment with a limited variety of vegetal species compared to their natural habitat. Buss (1961) reported 20 browse species found in the stomachs of 79 wild African elephants from savannah in Uganda. Grass was the main food consumed, and leaves, branches and fruits represented 10 percent of the stomach content. He also reported the consumption of succulents and herbaceous plants such as aloe, cotton and papyrus which are not provided in captivity. 
270 Although vegetable species were less diversified in the wild than at the zoo, the shape, size and

271 distribution of the pieces were similar for all the types of vegetables. In our study the availability

272 of each food type was well known by the elephants as well as their localization. The food

273 distribution was designed to minimize competition between animals and under these conditions

274 we expected the elephants to have low constraints to express their own behavioural feeding

275 strategy.

276 Despite a limited variety of foods, the elephants' diet encompassed different types of items. Hay

277 was the main component and was available ad libitum, branches of different sizes and pieces of

278 vegetables were distributed periodically in the course of the light period whereas slices of apples

279

280

281

282

283

284

were specifically given to the elephants during the opening of the doors. Our results revealed an outright link between food items and behaviours. For instance branches were mainly grasped and their manipulation usually entailed torsion to break them. Branches were the only food item implying an adjustment when they were too long and thick to be contained entirely into the mouth. We were unable to find any significant differences in the manipulation of branches according to their diameter, suggesting the relevance of the structure of an item more than its size in the adopted feeding strategy. To our knowledge, the diameter of the branches has never been studied in relation to their manipulation by elephants. Wild African elephants have been observed selecting branches and foliage of tall and frequently used trees (Smallie \& O'Connor, 2000). This resource hedging shaped the foliage production and increased the short-term food available quantity. Nevertheless, captive elephants have ad libitum resources and rarely feed on living plants. Thus, a hedging strategy has no meaning in captive populations. Hart et al. (2001) reported branches modification by wild and captive Asian elephants in order to get rid of flies. They did not mention the diameter, only the length of the branch and the process were reported. 
293 To break a side branch, elephants used their foot to maintain the rest of the branch on the ground.

294 The 0.75-2 meters-length side branch was used as a tool against flies and then was eaten or

295 dropped. Our study focused on the uses of the trunk, hence we did not report the involvement of

296 feet in the feeding processes. Nonetheless, from our personal observations, it is worth noting that

297 elephants scarcely implied their foot during food manipulation. They preferred to maintain

298 branches with their tusks or in their mouth.

299 The hay was pinched or wrapped, and it was very often shaken and bundled. Those two

300 behaviours were observed also with other food items but more rarely. Generally, they were

301 undertaken to remove sand or to improve the grip. Surprisingly, pieces of apples and vegetables

302 were managed in a similar way. Elephants pinched them with the fingers of the trunk, and more

303 rarely gathered and wrapped them, in order to take several pieces at once. These results

304 suggested that the small size of the food item was more determinant than its shape (slice vs

305 piece). Besides, the way of delivery of the food items seemed not to be decisive in the selection

306 of the feeding strategy. Racine (1980) also observed the manipulative strategies of captive Asian

307 and African elephants with different kinds of food items (apples, oranges, watermelons). He

308 correlated the different strategies with the trunk morphology (i.e. smaller fingers in Asian than

309 African elephants) and the size of the food. Small items easily maintained in the distal part of the

310 trunk were pinched while other strategies were employed with bigger items, mostly grasping.

311 One alternative strategy, which we did not mention in our behavioural repertoire, was described

312 by Racine (1980) as a position referring to "a golf ball on a tee". The elephants maintained the

313 item on their opened fingers and then pushed up the food to their mouth. The distance between

314 the elephant and the food might also impact the manipulative strategy, nearer food items being

315 more often grasped than distant items (Racine, 1980). In our study, no distance-depend strategy 
316 appeared. Elephants used predominantly the pinch behaviour to grip vegetable pieces either in

317 front of them or outside the enclosure. We observed that grasping movement was more related to

318 the quantity of items than to their distance. Grasping was mainly performed to catch several

319 items at once. One similarity which our observations share with Racine's is the predominance of

320 pinching behaviour to catch food against walls. In this situation, the grasping movement can be

321 constraining, and we argue that pinching is a more efficient strategy. Finally, we expected that

322 substrate characteristics should influence the vegetables feeding strategy. Indeed, grasp

323 movement was exclusively observed on the cement-flooring around the enclosure. Grasping on

324 the sand-flooring would certainly gather more sand than vegetable pieces and dramatically

325 reduce gripping efficiency.

326 Elephants are not the only animals changing their strategy depending on the item properties. This

327 research domain has been extensively studied in primates, showing how the properties of the

328 food (size, mobility) affected gripping kinematics and general strategies, such as the use of the

329 mouth versus the hands or the various techniques with hands (Nekaris, 2005; Peckre et al.,

330 2019a; Peckre et al., 2019b; Petter, 1962; Pouydebat et al., 2009; Pouydebat \& Bardo, 2019;

331 Scheumann et al., 2011; Toussaint et al., 2013; Toussaint et al., 2015). It is really interesting to

332 demonstrate that the adaptation of gripping techniques is not limited to the hand, but can be

333 addressed in other prehensile organs (Brunon et al., 2014; Sustaita et al., 2013).

334 Although the elephants shared common behavioural repertoires, they differed in the proportion

335 of the usage of those common behaviours, at least when they were eating hay. In group A, inter-

336 individual differences emerged in four of the five major behaviours observed (Figure 4). Only

337 the proportion of bundling was similarly used by the four elephants. It is worth noting that all the

338 elephants compared pairwise differed significantly at least in the use of one behaviour, and pinch 
339 was the behaviour with the most important inter-individual variability. Similar results were

340 found within group B. The two elephants used differently the grasp, bundling and bring to mouth

341 behaviours whereas they performed shake and pinch movements with the same proportion

342 (Figure 4). Shake was more used by both females in group B than females of group A with the

343 exception of Tana (A3). Yet, despite the two groups were in different enclosures in the same

344 building, there was no clear difference in the quality of the hay or in the pattern of hay

345 distribution that could explain this difference. In our study we reported behaviours as events and

346 we did not consider their duration. In our ethogram, we defined most of the behaviours at the

347 movement level and consequently, they were usually performed quickly. However equal weight

348 was given to short and long movements, which could have inhibited deeper inter-individuals

349 differences.

350 One of the elephant of group B (N'Dala, elephant B2) became blind one year before the

351 observations and we expected that this female could have developed specific strategies. The

352 difference between the two females in the group B was the highest for grasping, as the blind

353 female displayed distinctly less grasp behaviour than the other. The performances of the blind

354 female did not present explicit differences with the other elephants, and we were unable to show

355 the emergence of a specific strategy when eating hay. Possibly, the sense of sight plays a

356 secondary role in elephant feeding, olfaction and haptic senses may be more important and the

357 trunk is properly equipped. Moreover, since observations were made inside the building, in

358 which the limited space was well known to the elephants and no specific behavioural strategy

359 was required for a blind elephant. Only a comparison with the behaviour of this individual before

360 the occurrence of blindness could have revealed a behavioural modification. In human, brain

361 plastic adaptation to blindness has been extensively investigated. The compensation of the loss of 
362 eyesight seems to be generated by complex tasks only (Gizewski et al., 2003) but the over-

363 development of the other senses in early- and late-blind people failed to win unanimous support.

364 Opposite results emerged on exacerbated tactile capabilities and olfactory sense (Sathian \&

365 Stilla, 2010). The outcome appeared to depend on the task and the practice. In addition, a recent

366 large-scale study found no difference between early-, late-blind and sighted people in different

367 olfactory tests (Sorokowska, 2016). We consider cautiously those results because of the poor

368 vision of elephants and their far more accurate sense of smell than the one of humans.

369 Authors studying different species tried to explain the inter-individual differences they noted in

370 their experiments. Racine (1980) reported different strategies for the six elephants he observed.

371 He proposed three explanations of variation in individual behaviours: morphology, learning and

372 captivity. He studied both Asian and African elephants, with different shapes of the distal part of

373 the trunk and an effective difference in the use of pinch and grasp behaviours. The trunk

374 morphology of our elephants was less variable, with the exception of the very short ventral

375 finger of Ashanti which recalled an Asian-like trunk. Yet, her feeding strategy was not

376 significantly different from the other individuals, so the morphology cannot be the only factor

377 explaining variation in behaviour. The cohabitation of closely related species from different

378 locations and with different backgrounds can lead to the transmission of behavioural wonts and

379 enlargement of the repertoire (Galef \& Giraldeau, 2001). African elephants living in captivity

380 with Asian elephants integrated the use of foot in items manipulation (Racine, 1980). Elephants

381 are fast learners (Plotnik et al., 2011) and gathering social animals may homogenize their

382 catalogue and frequencies in the usage of feeding behaviours. Yet our results failed to show a

383 group-level similitude. For instance the side pinch behaviour was observed during vegetables

384 and apples feeding but was removed from the analysis because of a low number of occurrences. 
385 This behaviour was favoured over the pinch behaviour by some individuals including Ashanti

386 (A2) and Marjorie (B1). They originated from different locations and were housed separately at

387 the zoo. Thus it is probable that the side pinch behaviour appeared independently without

388 transmission between our elephants. We can hypothesize that behavioural learning occurs when

389 a behaviour is more efficient than the previously used strategy. However, we would need further

390 information about their early life to investigate this possibility.

391 Gripping variability has been studied in mammals as well as in other taxa (see Sustaita et al.,

3922013 for a review). Pigeons (Columba livia) have been shown to adapt their pecking movement

393 to the food size and accessibility (Siemann \& Delius, 1992). Opening of their mandibles

394 depended on the size of the seed and the gripping and pulling strength differed between free and

395 attached seeds to the substrate. Recorded movements were highly variable between individuals.

396 This variability was explained mainly by learning as pigeons consume highly diverse food and

397 forage in diverse situations. In our study, we highlighted the influence of the food shape on the

398 feeding strategy, but we raised no evidence of the impact of attached food. Different strategies

399 could emerge in response to more hardly obtainable items. In captivity, the feeding conditions

400 are unidentical to conditions in the wild, where the food is usually attached to trees or substrate.

401 In more naturalistic conditions, elephants could demonstrate a larger repertoire of behaviours

402 aiming the processing of living plants into bite-size items. The availability of food in captivity

403 could inhibit natural behaviours and more pronounced inter-individual differences in food

404 acquisition.

405 Gripping behaviours play an essential role in locomotion, feeding, and reproduction in a great

406 diversity of tetrapod vertebrates, but has received relatively little attention outside of the

407 anthropological, primatological and biomedical literature (Sustaita et al., 2013). Although the 
408 ability to reach for food or prey or substrate, to hold it in a forepaw, or manipulate it with the

409 digits is sophisticated in primates, gripping abilities and manipulation can also be highly

410 developed at least in other mammals. Gripping modalities may differ from group-to-group, but

411 they share common muscles bases and selective pressures (Sustaita et al., 2013). We need to

412 explore them much more across taxa, outside primates.

414 Conclusion

415 Proboscideans are characterized by their big size and especially by their prehensile and sensitive

416 trunk. It is usually compared with the primates' hand, and similarly to this group, elephants show

417 individual strategies. In our study we focused on feeding behaviours and we highlighted the

418 important influence of the food properties on the gripping strategies. The elephants identified the

419 item and adapted their movement to manipulate it efficiently. The same behaviours were entailed

420 to consume pieces of vegetables and apples or branches of different diameters, leading to the

421 conclusion that the overall shape and size of the food is determinant for the employed strategy.

422 Inter-individual differences in behaviour were especially clear during hay consumption. Despite

423 a similar repertoire, each elephant differed from the others in the frequency of at least one

424 behaviour. Neither blindness of N'Dala nor the particular trunk morphology of Ashanti seemed

425 to be the factors of this variation. Inter-individual behavioural differences could be triggered by

426 early learning or intrinsic preferences. However, further observations are needed to investigate

427 the impact of preferences on feeding strategies and behavioural variability. Gripping

428 performance might play a more critical role in tetrapod evolution than currently understood.

429 More comprehensive data on gripping behaviour and functional morphology, from a greater

430 diversity of taxa, are required to test this in a rigorous phylogenetic framework, and elephants

431 have to be included in these studies.

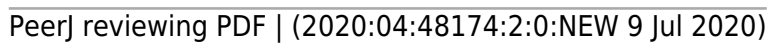




\section{Acknowledgements}

434 We gratefully thank the ZooParc of Beauval who owns the elephants and welcomed our project.

435 Experiments were conducted with the help of the keepers under the direction of Yann Ménager.

436 All our thanks go to him and Nathan Durand, Amaury Boutier, Matthieu Villemain, Matthieu

437 Fromet, Mathieu Hysbergue, Mégane Marron and Clément Langles. We finally thank the ATM

438 of The National Museum of Natural History and funding CNRS 80 PRIME for the funding. 
440

441

442

443

444

445

446

447

448

449

450

451

452

453

454

455

456

457

458

459

460

461

462

\section{REFERENCES}

Adams, J., \& Berg, J. K. (1980). Behavior of female African elephants (Loxodonta africana) in captivity. Applied Animal Ethology, 6(3), 257-276. https://doi.org/10.1016/0304-3762(80)90027-9

Altmann, J. (1974). Observational Study of Behavior: Sampling Methods. Behaviour, 49(3-4), 227-266. https://doi.org/10.1163/156853974X00534

Bardo, A., Borel, A., Meunier, H., Guéry, J.-P., \& Pouydebat, E. (2016). Behavioral and functional strategies during tool use tasks in bonobos. American Journal of Physical Anthropology, 161(1), 125-140. https://doi.org/10.1002/ajpa.23015

Bardo, A., Cornette, R., Borel, A., \& Pouydebat, E. (2017). Manual function and performance in humans, gorillas, and orangutans during the same tool use task. American Journal of Physical Anthropology, 164(4), 821-836. https://doi.org/10.1002/ajpa.23323

Bardo, A., Pouydebat, E., \& Meunier, H. (2015). Do bimanual coordination, tool use, and body posture contribute equally to hand preferences in bonobos? Journal of Human Evolution, 82, 159-169. https://doi.org/10.1016/j.jhevol.2015.02.015

Brunon, A., Bovet, D., Bourgeois, A., \& Pouydebat, E. (2014). Motivation and manipulation capacities of the blue and yellow macaw and the tufted capuchin: A comparative approach. Behavioural Processes, 107, 1-14. https://doi.org/10.1016/j.beproc.2014.06.006

Buss, I. O. (1961). Some Observations on Food Habits and Behavior of the African Elephant. The Journal of Wildlife Management, 25(2), 131. https://doi.org/10.2307/3798671

Christel, M. (1993). Grasping techniques and hand preferences in Hominoidea. In H. Preuschoft \& D. J. Chivers (Eds.), Hands of Primates (pp. 91-108). Springer. https://doi.org/10.1007/978-3-70916914-8_7 
463 Christel, M. I., \& Billard, A. (2002). Comparison between macaques' and humans' kinematics of 464 prehension: the role of morphological differences and control mechanisms. Behavioural Brain 465 Research, 131(1), 169-184. https://doi.org/10.1016/S0166-4328(01)00372-2

466

467

468

469

470

471

472

473

474

475 Objects? International Journal of Primatology, 19(1), 165-194. https://doi.org/10.1023/A:1020319313219

Crast, J., Fragaszy, D., Hayashi, M., \& Matsuzawa, T. (2009). Dynamic in-hand movements in adult and young juvenile chimpanzees (Pan troglodytes). American Journal of Physical Anthropology, 138(3), 274-285. https://doi.org/10.1002/ajpa.20925

Fabre, A.-C., Cornette, R., Slater, G., Argot, C., Peigné, S., Goswami, A., \& Pouydebat, E. (2013). Getting a grip on the evolution of grasping in musteloid carnivorans: a three-dimensional analysis of forelimb shape. Journal of Evolutionary Biology, 26(7), 1521-1535. https://doi.org/10.1111/jeb.12161

Galef, B. G., \& Giraldeau, L.-A. (2001). Social influences on foraging in vertebrates: causal mechanisms and adaptive functions. Animal Behaviour, 61(1), 3-15. https://doi.org/10.1006/anbe.2000.1557

Gizewski, E. R., Gasser, T., de Greiff, A., Boehm, A., \& Forsting, M. (2003). Cross-modal plasticity for sensory and motor activation patterns in blind subjects. Neurolmage, 19(3), 968-975. https://doi.org/10.1016/S1053-8119(03)00114-9

Haakonsson, J. E., \& Semple, S. (2009). Lateralisation of trunk movements in captive Asian elephants ( Elephas maximus ). Laterality: Asymmetries of Body, Brain and Cognition, 14(4), 413-422. https://doi.org/10.1080/13576500802572442

Hart, B. L., Hart, L. A., McCoy, M., \& Sarath, C. R. (2001). Cognitive behaviour in Asian elephants: use and modification of branches for fly switching. Animal Behaviour, 62(5), 839-847. https://doi.org/10.1006/anbe.2001.1815 
487

488

489

490

491

492

493

494

495

496

497

498

499

500

501

502

503

504

505

506

507

508

509

510

Hoffmann, J. N., Montag, A. G., \& Dominy, N. J. (2004). Meissner corpuscles and somatosensory acuity: The prehensile appendages of primates and elephants. The Anatomical Record, 281A(1), 11381147. https://doi.org/10.1002/ar.a.20119

Holm, S. (1979). A Simple Sequentially Rejective Multiple Test Procedure. Scandinavian Journal of Statistics, 6(2), 65-70. JSTOR.

Jones-Engel, L. E., \& Bard, K. A. (1996). Precision grips in young chimpanzees. American Journal of Primatology, 39(1), 1-15. https://doi.org/10.1002/(SICI)1098-2345(1996)39:1<1::AIDAJP1>3.0.CO;2-2

Kier, W. M., \& Smith, K. K. (1985). Tongues, tentacles and trunks: the biomechanics of movement in muscular-hydrostats. Zoological Journal of the Linnean Society, 83(4), 307-324. https://doi.org/10.1111/j.1096-3642.1985.tb01178.x

Murray E. Fowler, \& Susan K. Mikota. (2006). Biology, Medicine, and Surgery of Elephants. Murray E. Fowler, Susan K. Mikota.

Nekaris, K. A. I. (2005). Foraging behaviour of the slender loris (Loris lydekkerianus lydekkerianus): implications for theories of primate origins. Journal of Human Evolution, 49(3), 289-300. https://doi.org/10.1016/j.jhevol.2005.04.004

Peckre, L., Fabre, A.-C., Wall, C. E., Brewer, D., Ehmke, E., Haring, D., Shaw, E., Welser, K., \& Pouydebat, E. (2016). Holding-on: co-evolution between infant carrying and grasping behaviour in strepsirrhines. Scientific Reports, 6(1), 1-9. https://doi.org/10.1038/srep37729

Peckre, Louise R., Fabre, A.-C., Hambuckers, J., Wall, C. E., Socias-Martínez, L., \& Pouydebat, E. (2019). Food properties influence grasping strategies in strepsirrhines. Biological Journal of the Linnean Society, 127(3), 583-597. https://doi.org/10.1093/biolinnean/bly215

Peckre, Louise Rachel, Lowie, A., Brewer, D., Ehmke, E., Welser, K., Shaw, E., Wall, C., Pouydebat, E., \& Fabre, A.-C. (2019). Food mobility and the evolution of grasping behaviour: a case study in 
strepsirrhine primates. Journal of Experimental Biology, 222(20). https://doi.org/10.1242/jeb.207688

513 Petter, J. J. (1962). Ecological and Behavioral Studies of Madagascar Lemurs in the Field. Annals of the New York Academy of Sciences, 102(2), 267-281. https://doi.org/10.1111/j.17496632.1962.tb13645.x

Plotnik, J. M., Lair, R., Suphachoksahakun, W., \& de Waal, F. B. M. (2011). Elephants know when they need a helping trunk in a cooperative task. Proceedings of the National Academy of Sciences, 108(12), 5116-5121. https://doi.org/10.1073/pnas.1101765108

Pouydebat, E., \& Bardo, A. (2019). An interdisciplinary approach to the evolution of grasping and manipulation. Biological Journal of the Linnean Society, 127(3), 535-542. https://doi.org/10.1093/biolinnean/blz058

Pouydebat, E., Gorce, P., Coppens, Y., \& Bels, V. (2009). Biomechanical study of grasping according to

Pouydebat, E., Reghem, E., Borel, A., \& Gorce, P. (2011). Diversity of grip in adults and young humans the volume of the object: Human versus non-human primates. Journal of Biomechanics, 42(3),

Racine, R. (1980). Behavior Associated with Feeding in Captive African and Asian Elephants. Elephant, and chimpanzees (Pan troglodytes). Behavioural Brain Research, 218(1), 21-28. 1(5). https://doi.org/10.22237/elephant/1521731845 https://doi.org/10.1016/j.bbr.2010.11.021

Rasmussen, L. E. L., \& Munger, B. L. (1996). The sensorineural specializations of the trunk tip (finger) of the asian elephant,elephas maximus. The Anatomical Record, 246(1), 127-134. https://doi.org/10.1002/(SICI)1097-0185(199609)246:1<127::AID-AR14>3.0.CO;2-R 
533 Reghem, E., Tia, B., Bels, V., \& Pouydebat, E. (2011). Food Prehension and Manipulation in Microcebus

534 murinus (Prosimii, Cheirogaleidae). Folia Primatologica, 82(3), 177-188.

$535 \quad$ https://doi.org/10.1159/000334077

536 Sathian, K., \& Stilla, R. (2010). Cross-modal plasticity of tactile perception in blindness. Restorative

$537 \quad$ Neurology and Neuroscience, 28(2), 271-281. https://doi.org/10.3233/RNN-2010-0534

538 Scheumann, M., Joly-Radko, M., Leliveld, L., \& Zimmermann, E. (2011). Does body posture influence

539 hand preference in an ancestral primate model? BMC Evolutionary Biology, 11(1), 52.

$540 \quad$ https://doi.org/10.1186/1471-2148-11-52

541 Shoshani, J. (1998). Understanding proboscidean evolution: a formidable task. Trends in Ecology \& Evolution, 13(12), 480-487. https://doi.org/10.1016/S0169-5347(98)01491-8

543 Siemann, M., \& Delius, J. D. (1992). Variability of Forage Pecking in Pigeons. Ethology, 92(1), 29-50.

$544 \quad$ https://doi.org/10.1111/j.1439-0310.1992.tb00947.x

545 Smallie, J. J., \& O'Connor, T. G. (2000). Elephant utilization of Colophospermum mopane: possible

546 benefits of hedging. https://onlinelibrary.wiley.com/doi/full/10.1046/j.1365-2028.2000.00258.x

547 Sorokowska, A. (2016). Olfactory Performance in a Large Sample of Early-Blind and Late-Blind

$548 \quad$ Individuals. Chemical Senses, 41(8), 703-709. https://doi.org/10.1093/chemse/bjw081

549 Sustaita, D., Pouydebat, E., Manzano, A., Abdala, V., Hertel, F., \& Herrel, A. (2013). Getting a grip on

550 tetrapod grasping: form, function, and evolution. Biological Reviews, 88(2), 380-405.

$551 \quad$ https://doi.org/10.1111/brv.12010

552 Toussaint, S., Reghem, E., Chotard, H., Herrel, A., Ross, C. F., \& Pouydebat, E. (2013). Food acquisition on

553 arboreal substrates by the grey mouse lemur: implication for primate grasping evolution.

$554 \quad$ Journal of Zoology, 291(4), 235-242. https://doi.org/10.1111/jzo.12073

555 Toussaint, Séverine, Herrel, A., Ross, C. F., Aujard, F., \& Pouydebat, E. (2015). Substrate Diameter and

556 Orientation in the Context of Food Type in the Gray Mouse Lemur, Microcebus murinus:

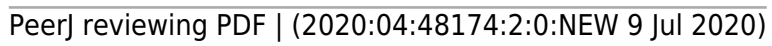


557 Implications for the Origins of Grasping in Primates. International Journal of Primatology, 36(3),

$558 \quad$ 583-604. https://doi.org/10.1007/s10764-015-9844-2

559 Yang, J., Pitarch, E. P., Potratz, J., Beck, S., \& Abdel-Malek, K. (2006). Synthesis and analysis of a flexible

560 elephant trunk robot. Advanced Robotics, 20(6), 631-659.

$561 \quad$ https://doi.org/10.1163/156855306777361631

562 


\section{Table $\mathbf{1}$ (on next page)}

Repertoire of feeding behaviours.

Blow, Search behaviors, Trunk to mouth, Contact to mouth and Drink behaviors were removed from the analysis. Pinch, Grasp, Bundling and Block behaviors are reported in Racine (1980), in which Bundling is called Cradling and vary a little bit in the observed uses. 


\begin{tabular}{|c|c|}
\hline BEHAVIOUR & DESCRIPTION \\
\hline Pinch & $\begin{array}{l}\text { Catch little items between the fingers of the trunk. Can } \\
\text { be helped by a breath }\end{array}$ \\
\hline Side pinch & $\begin{array}{l}\text { Catch little items between the fingers of the trunk } \\
\text { laying down on one side. Taking the item from the } \\
\text { side. Can be helped by a breath }\end{array}$ \\
\hline Blow & $\begin{array}{l}\text { Exhalation around an item, usually to clear lightweight } \\
\text { elements like hay or sand }\end{array}$ \\
\hline Grasp & $\begin{array}{l}\text { Wrap the trunk around a big item, which would be } \\
\text { difficult to maintain with one finger. Potential side } \\
\text { preference }\end{array}$ \\
\hline Torsion/Pressure & $\begin{array}{l}\text { Wrap and torsion of the trunk by creating a pressure } \\
\text { point, usually to break a branch }\end{array}$ \\
\hline Bundling & $\begin{array}{l}\text { Compact an item on the ventral part of the trunk once } \\
\text { or several times before pinching it and bringing it to } \\
\text { the mouth }\end{array}$ \\
\hline Shake & Shake vigorously a pinch held in the trunk \\
\hline Sweep & $\begin{array}{l}\text { Sweep with the side of the trunk to gather items before } \\
\text { catching them. Potential side preference }\end{array}$ \\
\hline Gather & $\begin{array}{l}\text { Gather or bring back items with the end of the trunk or } \\
\text { just the fingers. Potential side preference }\end{array}$ \\
\hline Pull & Pull an item to break it or separate from the others \\
\hline $\begin{array}{l}\text { Search on the } \\
\text { ground }\end{array}$ & $\begin{array}{l}\text { Separate items in a pile with the end of the trunk in } \\
\text { order to select and sample only a part }\end{array}$ \\
\hline Search in height & $\begin{array}{l}\text { Separate items in a net in height with the end of the } \\
\text { trunk in order to select and sample only a part }\end{array}$ \\
\hline Search in a box & $\begin{array}{l}\text { Separate items in an enrichment box with the end of } \\
\text { the trunk in order to select and sample only a part }\end{array}$ \\
\hline Trunk to mouth & $\begin{array}{l}\text { Trunk brought to the mouth without providing or } \\
\text { removing items }\end{array}$ \\
\hline Adjust & $\begin{array}{l}\text { Adapt the position of an item going out of the mouth, } \\
\text { usually a branch }\end{array}$ \\
\hline $\begin{array}{l}\text { Contact to } \\
\text { mouth }\end{array}$ & Brief touch of the mouth with the end of the trunk \\
\hline
\end{tabular}



Water suction and releasing into the mouth, trunk high-
positioned

Bring to mouth Bring a bite to the mouth in order to eat it

Block Wedge an item between the trunk and a tusk, to keep it from others or to manipulate it

1 
Figure 1

Contribution of the different variables (behaviours) to the first two components of the PCA.

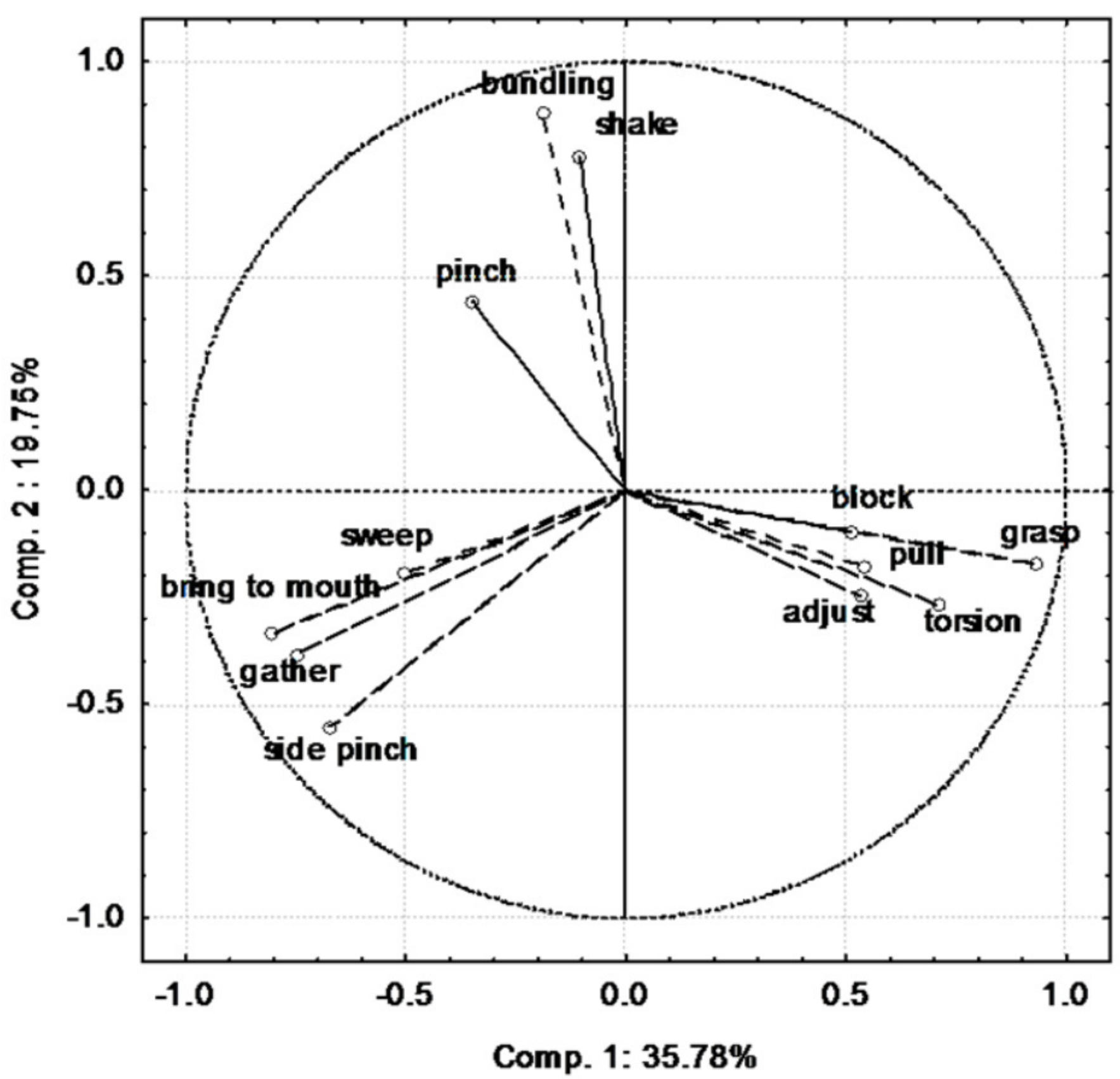


Figure 2

Plot of the food items in the two first dimensions of the PCA.

Each point of a given type of food item corresponds to a different elephant $(N=6)$.

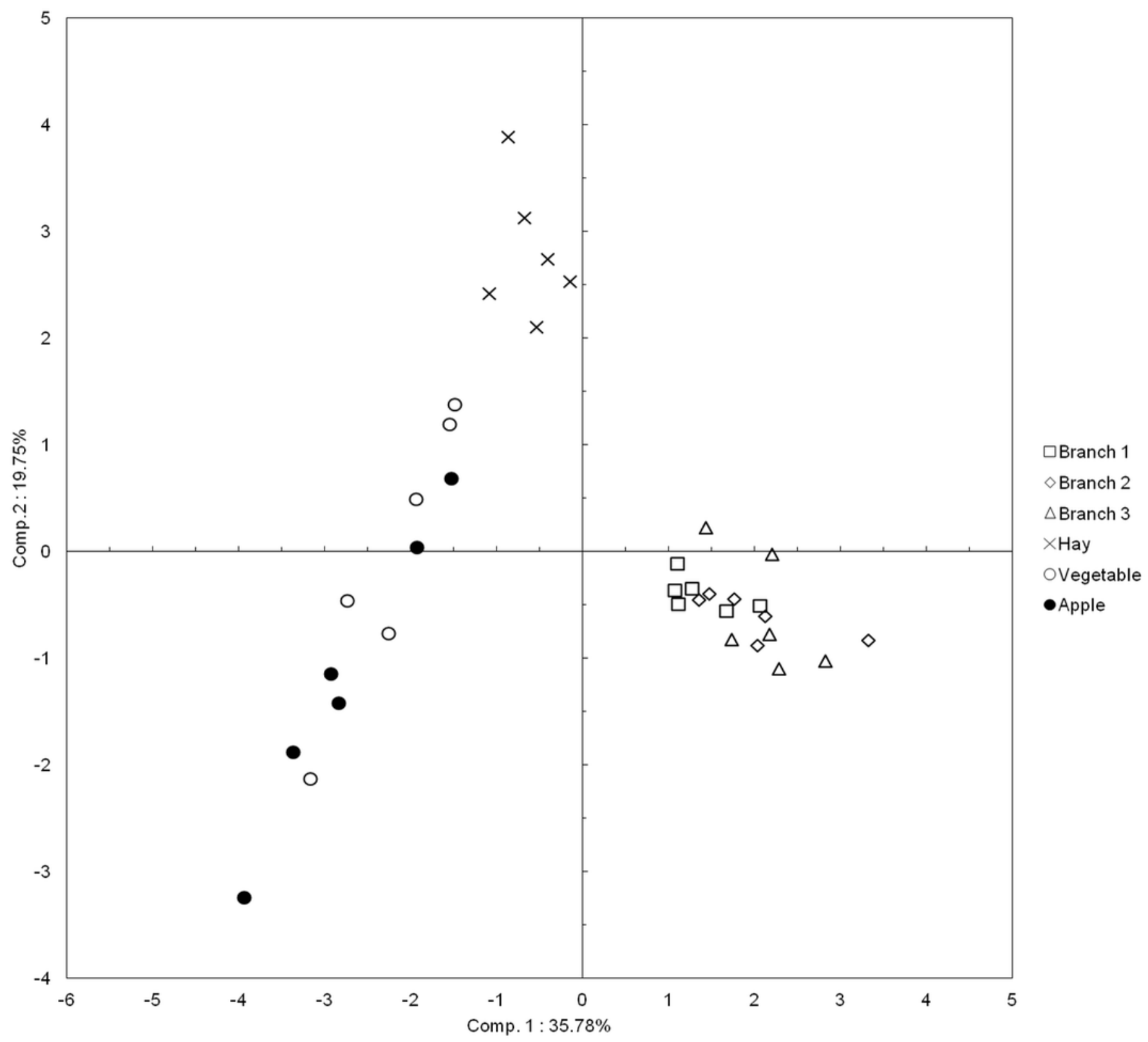


Figure 3

Proportions of occurrences of the different behaviors observed during feeding.

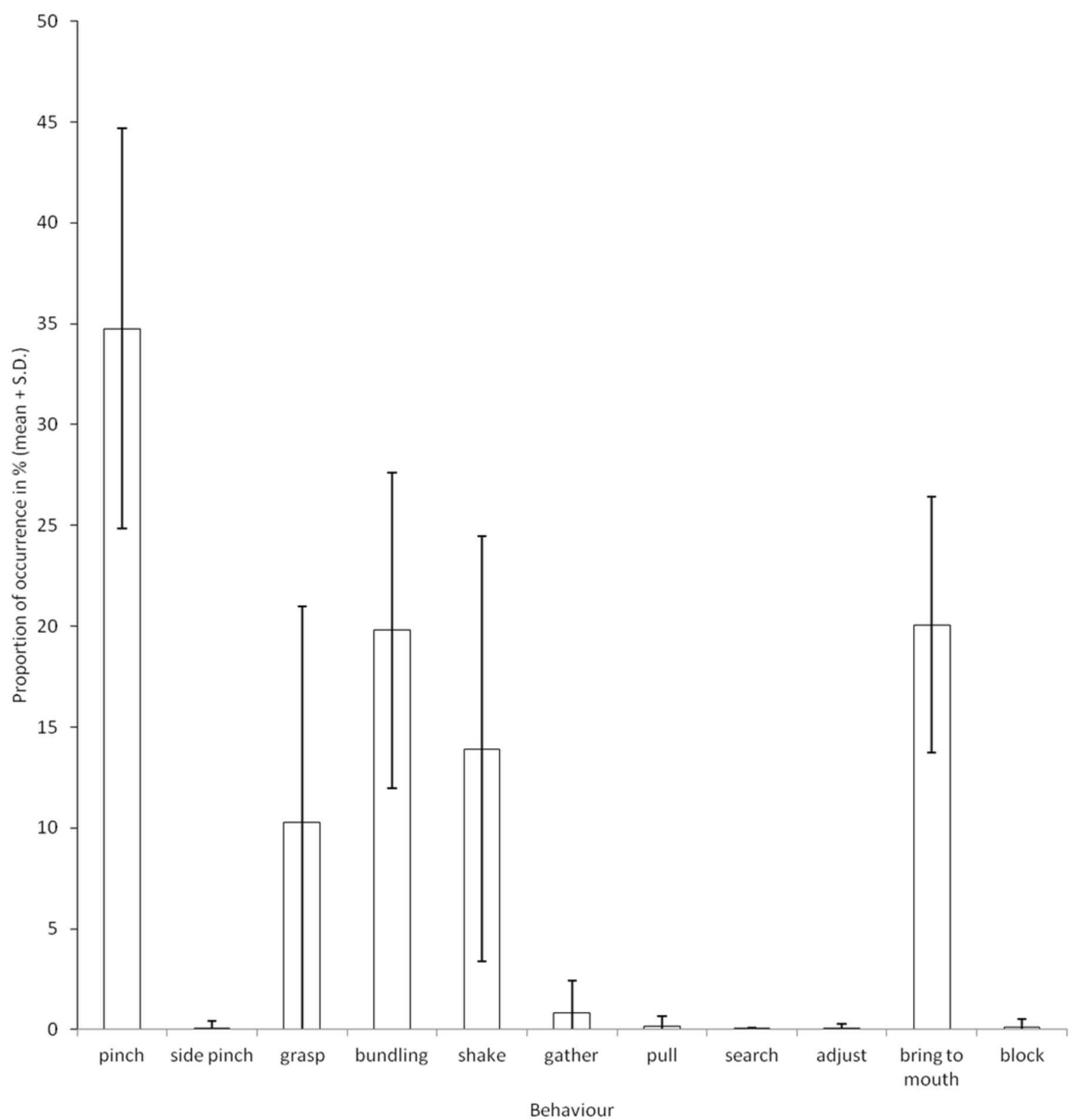




\section{Figure 4}

Individual differences in the use of the different behaviors when feeding on hay.

Each graph shows a given behavior (name at the top right of the box). The black bars correspond to the four elephants of the group A ( $\mathrm{A} 1$ to $\mathrm{A} 4$ ), and the white bars to the two elephants of group B. For group A, bars with no common letter differ significantly; significant differences between the two individuals of group $B$ are indicated by: $*(P<0.05)$ or *** $(P<$ 0.001 ). The number of samples varies between the individuals (A1: $N=12 ; \mathrm{A} 2: N=10 ; \mathrm{A} 3: N$ $=11 ; \mathrm{A} 4: N=9 ; \mathrm{B} 1: N=14$ and $\mathrm{B} 2: N=11)$. 


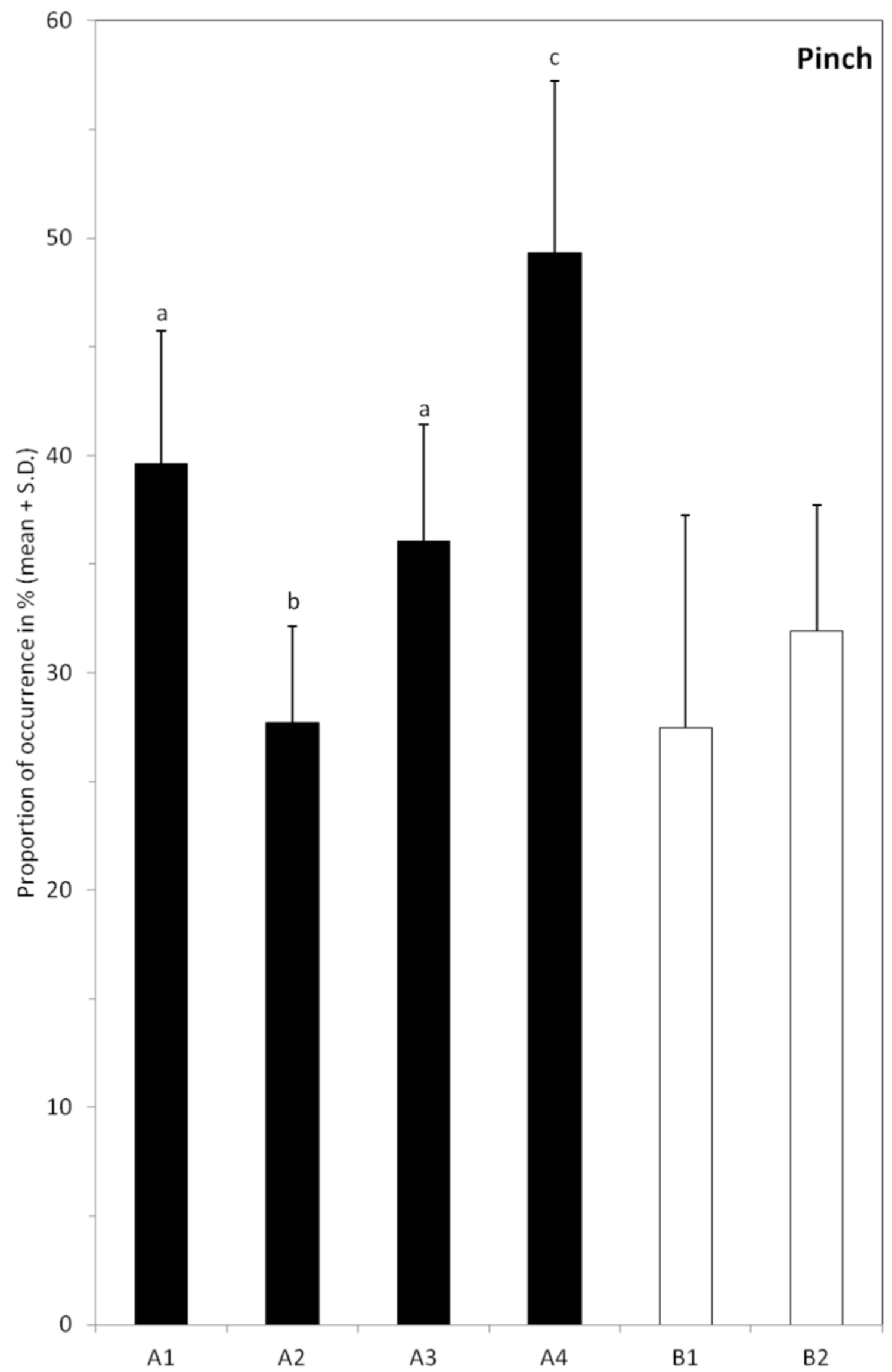

Peer) reviewing PDF | (2020:04:48174:2:0:NEW 9 Jul 2020) 


\section{Figure 5}

Individual differences in the use of the different behaviors when feeding on hay.

Each graph shows a given behavior (name at the top right of the box). The black bars correspond to the four elephants of the group A ( $\mathrm{A} 1$ to $\mathrm{A} 4$ ), and the white bars to the two elephants of group B. For group A, bars with no common letter differ significantly; significant differences between the two individuals of group $B$ are indicated by: $*(P<0.05)$ or *** $(P<$ 0.001 ). The number of samples varies between the individuals (A1: $N=12 ; \mathrm{A} 2: N=10 ; \mathrm{A} 3: N$ $=11 ; \mathrm{A} 4: N=9 ; \mathrm{B} 1: N=14$ and $\mathrm{B} 2: N=11$ ). 


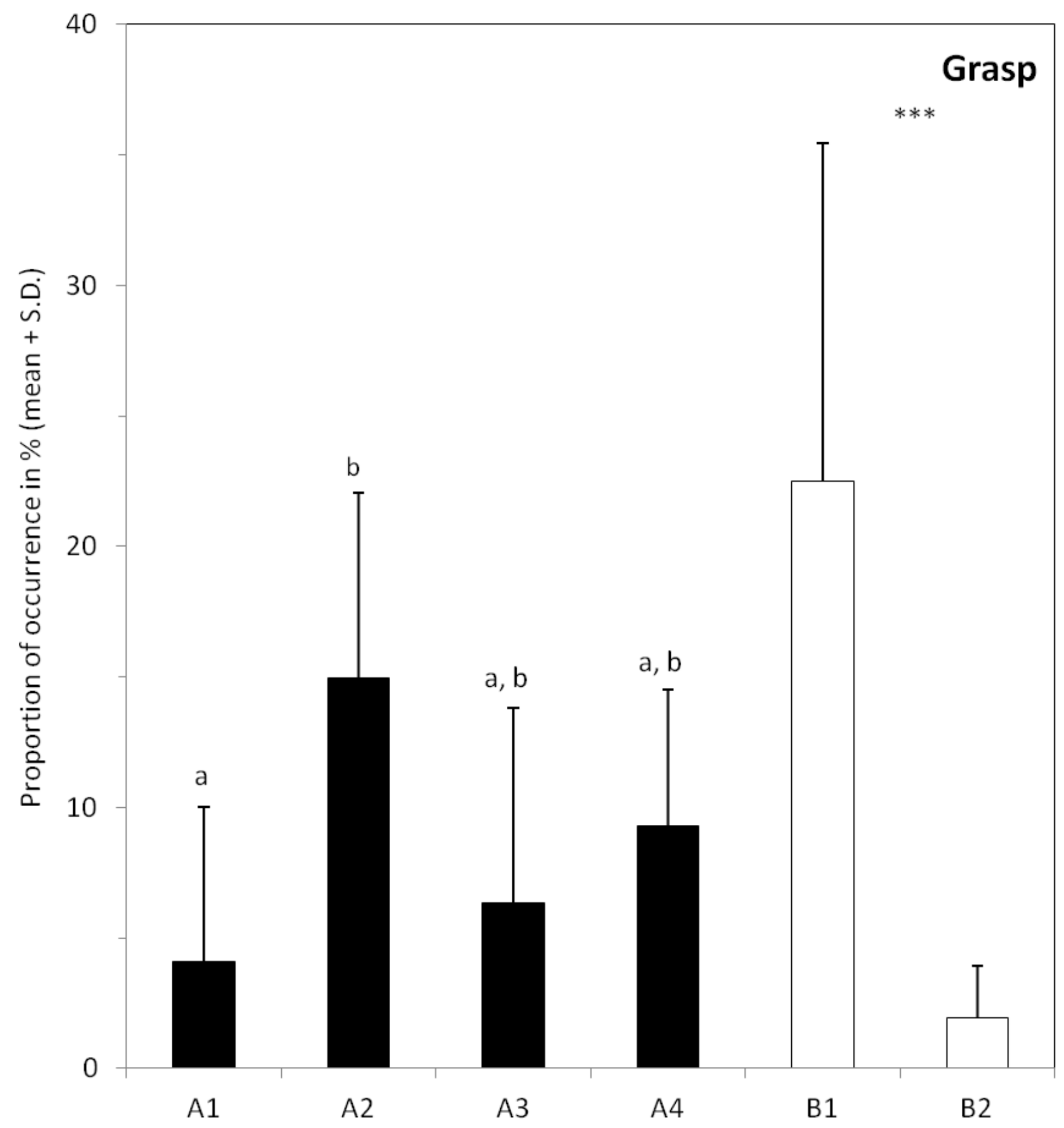




\section{Figure 6}

Individual differences in the use of the different behaviors when feeding on hay.

Each graph shows a given behavior (name at the top right of the box). The black bars correspond to the four elephants of the group A ( $\mathrm{A} 1$ to $\mathrm{A} 4$ ), and the white bars to the two elephants of group B. For group A, bars with no common letter differ significantly; significant differences between the two individuals of group $B$ are indicated by: $*(P<0.05)$ or *** $(P<$ 0.001 ). The number of samples varies between the individuals (A1: $N=12 ; \mathrm{A} 2: N=10 ; \mathrm{A} 3: N$ $=11 ; \mathrm{A} 4: N=9 ; \mathrm{B} 1: N=14$ and $\mathrm{B} 2: N=11$ ). 


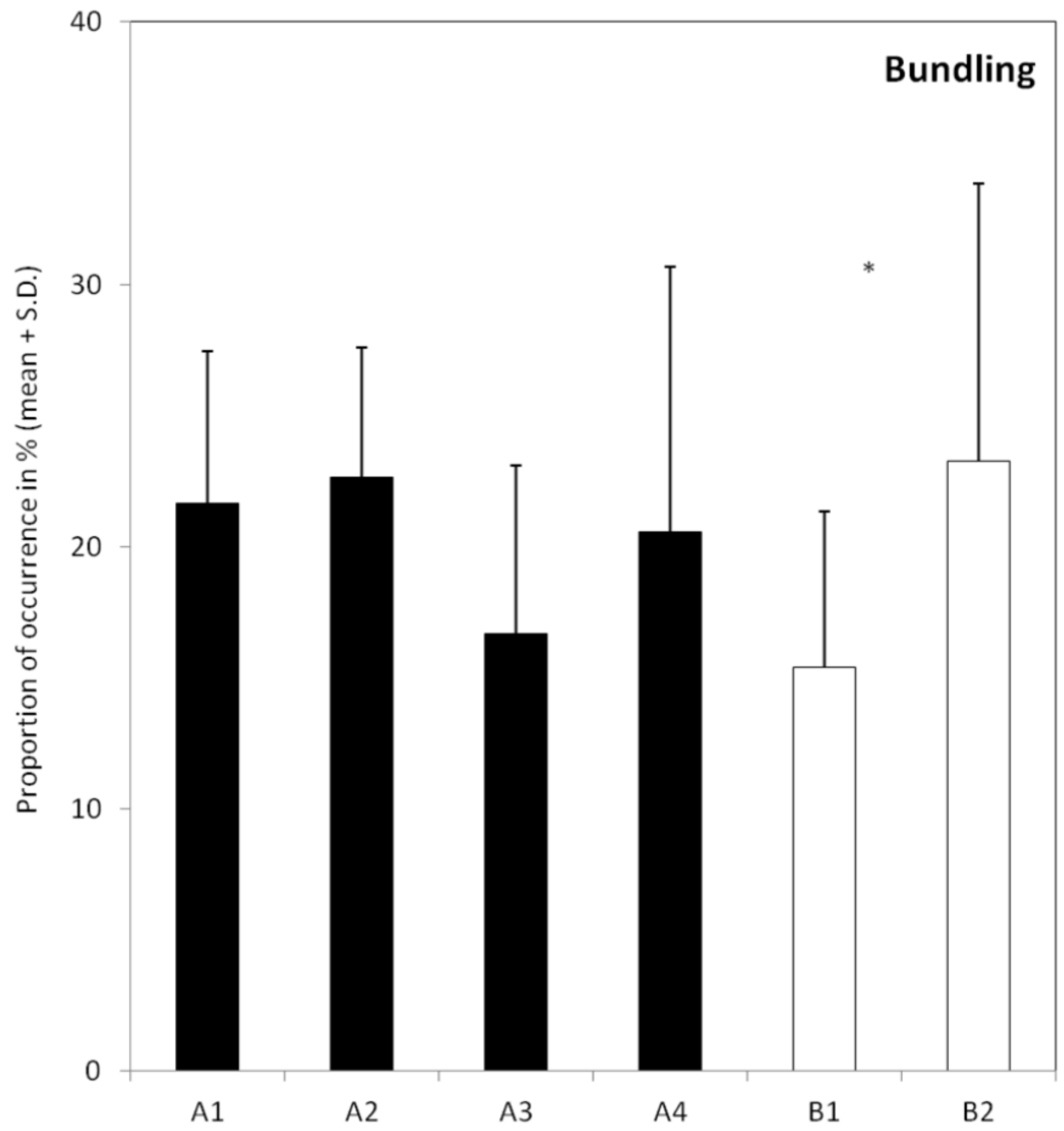




\section{Figure 7}

Individual differences in the use of the different behaviors when feeding on hay.

Each graph shows a given behavior (name at the top right of the box). The black bars correspond to the four elephants of the group A ( $\mathrm{A} 1$ to $\mathrm{A} 4$ ), and the white bars to the two elephants of group B. For group A, bars with no common letter differ significantly; significant differences between the two individuals of group $B$ are indicated by: $*(P<0.05)$ or *** $(P<$ $0.001)$. The number of samples varies between the individuals ( $\mathrm{A} 1: N=12 ; \mathrm{A} 2: N=10 ; \mathrm{A} 3: N$ $=11 ; \mathrm{A} 4: N=9 ; \mathrm{B} 1: N=14$ and $\mathrm{B} 2: N=11)$. 


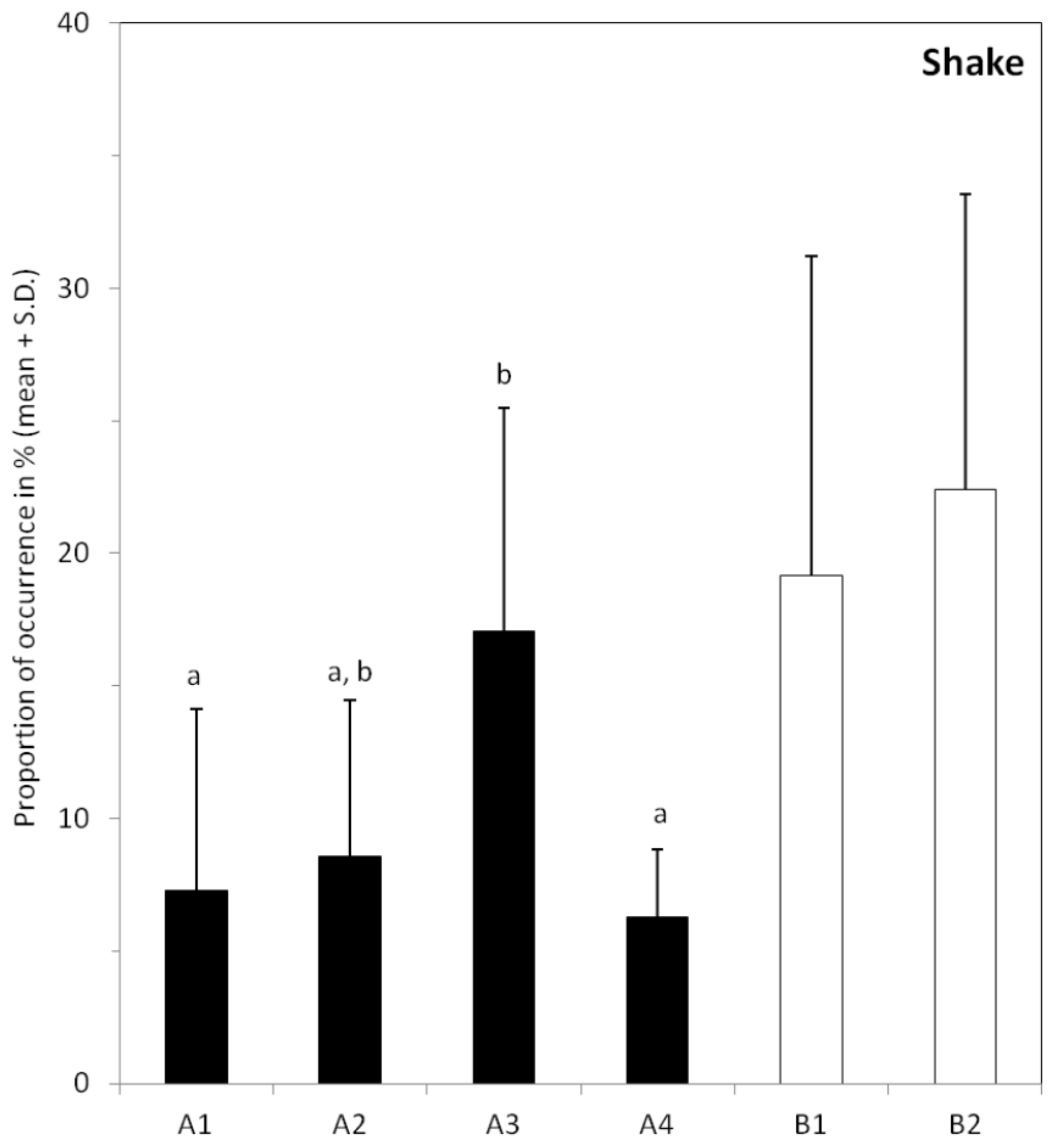




\section{Figure 8}

Individual differences in the use of the different behaviors when feeding on hay.

Each graph shows a given behavior (name at the top right of the box). The black bars correspond to the four elephants of the group $A$ ( $A 1$ to $A 4$ ), and the white bars to the two elephants of group B. For group A, bars with no common letter differ significantly; significant differences between the two individuals of group $B$ are indicated by: $*(P<0.05)$ or *** $(P<$ 0.001 ). The number of samples varies between the individuals (A1: $N=12 ; \mathrm{A} 2: N=10 ; \mathrm{A} 3: N$ $=11 ; \mathrm{A} 4: N=9 ; \mathrm{B} 1: N=14$ and $\mathrm{B} 2: N=11$ ). 


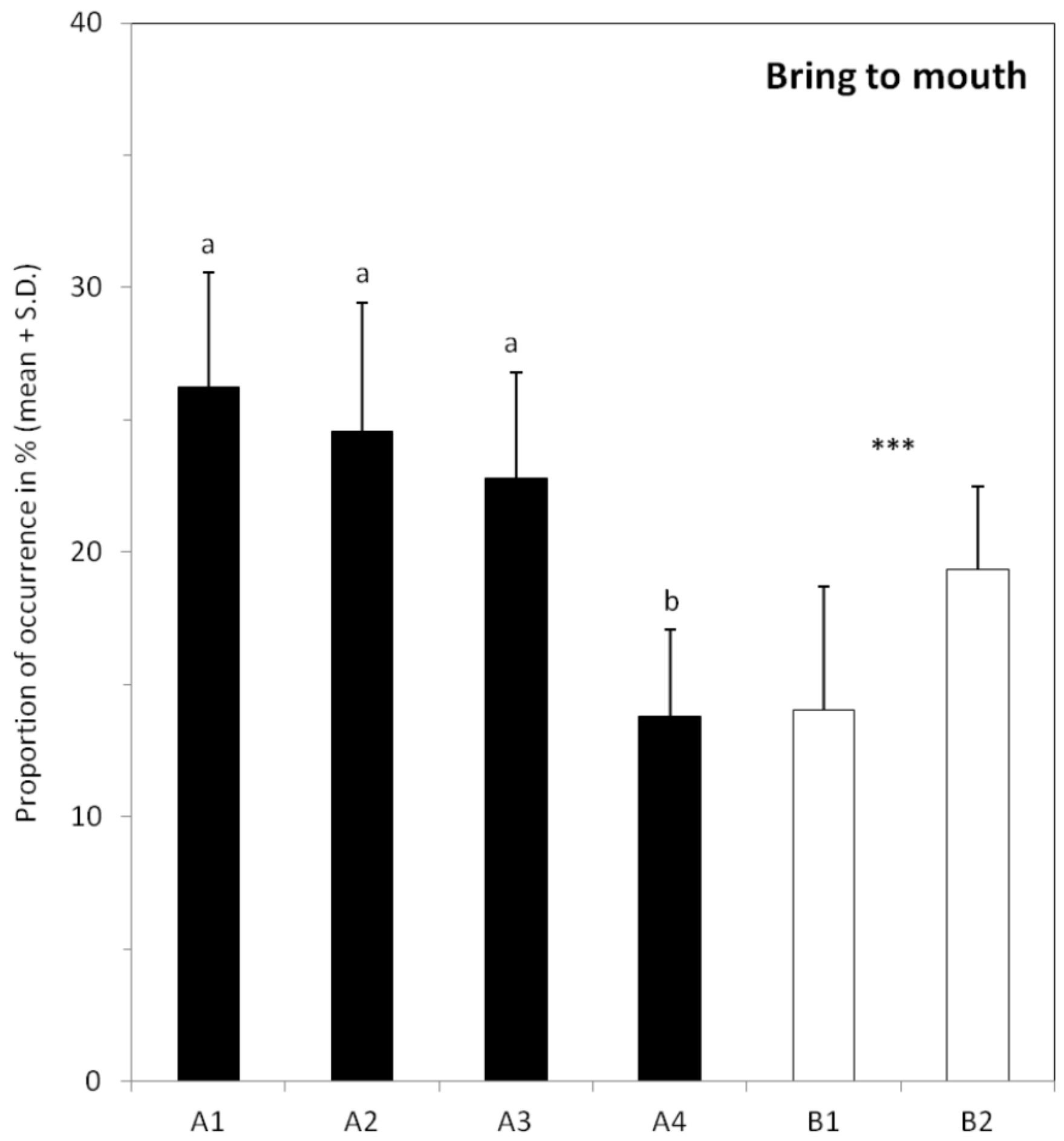

